\title{
REVISTA DE HUMANIDADES Y CIENCIAS SOCIALES
}

número 22 | julio-diciembre 2018 online ISSN 0719-3696 / ISSN 0718-655x

Alejandra Castillo

Sayak Valencia

valeria flores

María Belén Rosales

Marina Alvarado

Natalia Fischetti

Panchiba F. Barrientos

Márgara Millán

Verónica Schild

Luna Follegati Montenegro

Valentina Stutzin

Lieta Vivaldi

Nicolás Ried

\section{INTRODUCCIÓN}

Feminismos en América Latina. Introducción

Feminisms in Latin America. Introduction

\section{Artículos}

El Transfeminismo no es un Generismo

Transfeminism Is not a Genderism

Febriles alquimias del cuerpo. Una poética excrementicia

Febrile Alchemy of the Body. An Excremental Poetics

Ciberactivismo: praxis feminista y visibilidad política en \#NiUnaMenos Cyber-Activism: Feminist Praxis and Political Visibility in \#NiUnaMenos

Feminismos del Sur. Alusiones / Elusiones / Ilusiones

Southern Feminisms. Allusions / Elusions / Illusions

Sexo, género y mujeres: tensiones y quiebres desde la filosofía feminista Sex, Gender, and Women: Tensions and Disruptions from the Feminist Philosophy

La eclosión del sujeto del feminismo y la crítica de la modernidad capitalista The Eclosion of Feminism's Subject and the Critique of Capitalist Modernity

\section{ENTREVISTA}

Contingencia, democracia y neoliberalismo: reflexiones y tensiones a partir del movimiento feminista en la actualidad

Contingency, Democracy, and Neoliberalism: Reflections and Tensions from the Feminist Movement Today

\section{RESEÑAS}

Judith Butler, Zeynep Gambetti y Leticia Sabsay, eds. Vulnerability in Resistance. Durham NC: Duke University Press, 2016. 352 pp. ISBN 9780822362906

Judith Butler. Notes Toward a Performative Theory of Assembly.

Cambridge MA: Harvard University Press, 2015. 248 pp. ISBN 9780674967755 


\title{
Sexo, género y mujeres: tensiones y quiebres desde la filosofía feminista
}

\author{
Panchiba F. Barrientos ${ }^{1}$ \\ Universidad DE GHILE
}

Recibido: 27 de marzo de 2018

Aceptado: 22 de junio de 2018

\begin{abstract}
Resumen
Este texto busca proponer caminos de lectura posibles para acercarse a los modos en los que han sido desarrollados los conceptos sexo, género y mujeres desde las filosofias feministas contemporáneas siguiendo, para ello, una genealogía amplia que se reconoce marcada por el posestructuralismo y la crítica postmoderna, así como también por los feminismos ligados al horizonte cultural de las mujeres de color y la teoría queer. La propuesta central de este texto busca tensionar las categorías sexo, género y mujeres, interrogándose acerca de posibilidades que surgen, desde las filosofías feministas, para construir modos de lo político que nos impulsen a expandir nuestros compromisos con las nociones de reconocimiento, sujeto y diferencia.
\end{abstract}

\section{Palabras clave}

Sexo, Género, Mujeres, Filosofía feminista.

1 Candidata a doctora en Filosofía por la Universidad de Chile (Santiago, Chile). Correo electrónico: panchiba@gmail.com. 


\title{
Sex, Gender, and Women: Tensions and Disruptions from the Feminist Philosophy
}

\begin{abstract}
This article aims to propose possible ways to approach some aspects in which the concepts of sex, gender, and women have been developed by contemporary feminist philosophies, following a broad genealogy marked off by post-structuralist and postmodern criticisms, as well as by feminisms linked to the cultural horizon of women of color and queer theory. The central proposition of this article stresses the categories of sex, gender and women, in order to ask about the possibilities offered by feminist philosophies for the construction political modalities that propel us to expand our commitments with the notions of recognition, subject, and difference.
\end{abstract}

\section{Keywords}

Sex, Gender, Women, Feminist Philosophy. 


\section{Introducción}

En este artículo me interesa reflexionar sobre las formas en las que las discusiones contemporáneas en torno a los conceptos sexo, género y mujeres son disputados al interior de los marcos teóricos ligados a las filosofias feministas. Este trabajo da cuenta de una apuesta de lectura que busca abrir una ruta posible de debate, y en ningún caso pretende agotar los modos desde los que podemos aproximarnos a estos conceptos, ni proponer un canon de voces único o cerrado. A lo largo de este texto, pondré especial atención en los debates desarrollados desde los horizontes reflexivos de las filosofias feministas ligadas al postestructuralismo y a la crítica postmoderna, intentando dar cuenta de los matices, quiebres y preguntas a través de los cuales las tensiones entre las categorías sexo, género y mujeres han sido desplegadas y articuladas.

La filosofia feminista se ha conformado a partir de una mirada crítica del sujeto filosófico moderno, que asume lo universal como espacio del conocimiento absoluto, y que actúa ocultando su sesgo masculino y particular bajo la apariencia de lo neutro y desplazando a lo femenino como lo otro no representable. "La crítica contemporánea define la feminidad como la otra cara de la masculinidad, su radical o reprimido y, en el mejor de los casos, irrepresentable otro: de ahí la idea de la feminidad como el límite, o el horizonte, del logocentrismo occidental"2. Así, las reflexiones teóricas impulsadas por las filosofias feministas deben ser entendidas como un esfuerzo por evidenciar y romper "el silencio que ha marcado por mucho tiempo, y continúa marcando, la existencia material e intelectual de las mujeres" ${ }^{3} \mathrm{y}$, al mismo tiempo, como una denuncia a través de la cual se busca poner en evidencia que una teoría que no incorpora la experiencia de las mujeres, y sus múltiples diferencias, fortalece un conjunto de mecanismos que fomentan diversos modos de exclusión e invisibilidad. Desde aquí se vuelve urgente desmontar los límites desde los que hemos aprendido a pensar sobre el poder, el reconocimiento, la experiencia y la identidad.

El desarrollo de las filosofías feministas se inscribe en un marco teórico que desafía "los criterios que operan en la academia sobre lo que constituye teoría per se". Desde aquí surgen gestos y formas de nombrar que destacan el sentido de la figuración y la insistencia en lo autobiográfico, sin temor a arriesgar, en el gesto de escribir, los cimientos de un mundo diferente. Una filósofa feminista, no es un sujeto único o cerrado, sino más bien, alguien marcado por múltiples cruces, tensiones y posibilidades de nombrar(se), es "una pensadora creativa en la medida

2 Teresa De Lauretis, Diferencias. Etapas de un camino a través del feminismo (Madrid: Horas y Horas, 2000), 17.

3 Ibíd., 28.

$4 \quad$ Sara Ahmed, "Whose Counting?", Feminist Theory 1, no. 1 (2000): 99. 
en que produce nuevas formas de representación y definición del sujeto femenino" alguien dispuesto a asumir el cuerpo, la incomodidad, la urgencia y la localización como espacios fundamentales para el desarrollo de nuevas reflexiones filosóficas capaces de desafiar "los supuestos epistemológicos, morales y políticos de la razón occidental"6.

Las reflexiones emprendidas por las filosofias feministas tienen un doble anclaje. En estas propuestas teóricas se observa no sólo el deseo y la urgencia de demandar una transformación radical de las condiciones materiales, sociales y simbólicas en las que se desenvuelven las mujeres diariamente, sino también una apuesta sistemática por exponer los modos a partir de los cuales la propia categoría mujer es a la vez y articulada y disputada. Por lo tanto, el desafio que surge desde horizontes críticos ligados a las filosofías feministas es reconocer que "el concepto mujer es un problema" y que, por lo tanto, "nuestra propia definición se basa en un concepto que debemos deconstruir y desesencializar en todos sus aspectos".

\section{¿Se nace mujer o se llega a serlo?}

El segundo sexo, libro de Simone de Beauvoir publicado en 1949, da cuenta del desarrollo de un conjunto de preguntas que apuntan a pensar a las mujeres ya no como un conjunto de individuos de cuyas formas de discriminación y desigualdad habría que buscar pistas en la naturaleza o en la biología, sino más bien como un grupo delimitado de sujetos cuyos atributos son definidos y articulados a partir de una serie de estructuras sociales. A lo largo del libro de Simone de Beauvoir se describe, involucrando reflexiones ligadas a distintos campos del saber, la forma en que la existencia de las hembras humanas queda sujeta a "ese producto intermedio entre el macho y el castrado que se califica en femenino"9. Aquí las preguntas principales a las que se aboca De Beauvoir son qué es una mujer y cómo llega alguien a convertirse en una.

Las reflexiones y preguntas a través de las cuales Simone de Beauvoir problematiza el desplazamiento entre la supuesta certeza de lo natural -ser mujery las formas en las que esta naturaleza se condensa y materializa mediante las experiencias de las mujeres, en tanto individuos marcados por la diferencia, puede

5 Rosi Braidotti, Feminismo, diferencia sexual y subjetividad nómade (Barcelona: Editorial Gedisa, 2004), 39.

6 Cecilia Sánchez, "Institucionalidad de la filosofía en Chile: rutas y quiebres”, Solar 11, no. 2 (2015): 160.

7 Linda Alcoff, "Cultural Feminism versus Post-Structuralism: The Identity Crisis in Feminist Theory", Signs 13, no. 3 (1988), 405.

$8 \quad$ Ibíd., 406.

9 Simone de Beauvoir, El segundo sexo (Buenos Aires: Random House Mondadori, 2012), 207. 
rastrearse en un enunciado clave que, aún hoy, a casi setenta años de su aparición, nos sigue interpelando y movilizando reflexivamente: "No se nace mujer: se llega a serlo"10. Así lo señaló De Beauvoir cuando se vio enfrentada a pensar los modos en los que las mujeres son inscritas en el mundo social, mediante el despliegue de una serie de instituciones - la infancia, la maternidad, el matrimonio, ciertos tabúes y la delimitación de algunas perversiones- que construyen imaginarios del porvenir que se asocian a las mujeres, a fin de articularlas como tales al interior de horizontes culturales específicos.

El desafío propuesto por De Beauvoir nos conduce a pensar que las categorías identitarias que supuestamente habitamos, y a las que estamos tan acostumbradas -aun cuando creamos que se encuentran ancladas o ligadas a nuestra propia naturaleza-, son siempre resultado de una serie de estructuras y construcciones sociales que, al mismo tiempo que nos atraviesan, ayudamos a perpetuar. Así, lo que asumimos como propio de las mujeres, eso que reconocemos como característicamente femenino "es un momento puramente histórico del desarrollo de la categoría de sexo" ${ }^{11}$. A partir de sus investigaciones, Simone de Beauvoir insiste en que la historia y la etnografía deben ser pensados como los lugares centrales desde donde podremos impulsar los análisis que nos permitan "comprender de qué modo se ha establecido la jerarquía de los sexos"12. No existen datos biológicos que permitan explicar la subordinación de las mujeres, las diferencias que experimentamos a diario y las formas en las que vivimos dentro de los marcos regulatorios asociados a lo femenino y lo masculino. De Beauvoir insiste en que no existe un destino escrito de antemano y no hay una naturaleza última en la que debamos buscar la esencia de la mujer, más bien, debemos comprometernos a impulsar gestos conducentes a desmantelar las estructuras que sostienen el mito de la feminidad, puesto que decir mujer ya "no se trata de enunciar verdades eternas, sino de describir el fondo común sobre el cual se alza toda existencia femenina singular"13.

La escritora y teórica lesbiana Monique Wittig desafía la idea de que la identidad mujer sea un espacio deseable para la articulación y enunciación del sujeto político feminista, y con esto plantea una crítica que la distancia de forma radical tanto de Simone de Beauvoir como también de buena parte de las reflexiones del feminismo moderno. Esta autora advierte sobre los efectos nocivos y esencialistas emanados de la propia categoría mujer, proponiendo así un desafio importante para las formulaciones ligadas a las luchas por el reconocimiento como medios para

$10 \quad$ Ibíd., 207.

11 Judith Butler, "Variaciones sobre sexo y género. De Beauvoir, Wittig y Foucault", en Teoría feminista y teoría crítica. Ensayos sobre la política de género en las sociedades de capitalismo tardío, eds. Seyla Benhabib y Drucilla Cornell (Valencia: Edicions Alfons el Magnánim, 1990), 208.

12 Beauvoir, El segundo sexo, 63.

$13 \quad$ Ibíd., 205. 
alcanzar la liberación de las mujeres. Wittig argumenta que no es posible ser una mujer libre, puesto que mujer no es una categoría que pueda ser habitada por fuera de las estructuras normativas y materiales que la fundan. Para esta autora, la categoría de sexo es una estructura política e histórica que "funda la sociedad en cuanto heterosexual" " y que al mismo tiempo "une a las mujeres porque ellas no pueden ser concebidas fuera de esa categoría. Sólo ellas son sexo"15.

Retomando y llevando hasta el extremo la propuesta central de El segundo sexo, Monique Wittig da cuenta de la necesidad de resistir - teórica y políticamente- al proceso de llegar a ser mujer, que se nos muestra como inevitable y siempre lineal, en la propuesta de Simone de Beauvoir. Wittig argumenta que el hombre y la mujer constituyen categorías normativas innaturales, surgidas únicamente como "producto de una relación social" "16 y cuyo carácter es localizado e histórico. La propia existencia de la categoría mujer debe ser revisada, puesto que funda un mito -la Mujer- que oprime a las mujeres en cuanto clase y que sólo se vuelve posible al interior de una relación social específica, centrada en un contrato con un otro masculino. Desde la perspectiva ofrecida por Wittig, únicamente desmontando los mandatos normativos que reproducen la categoría de sexo y la integran naturalizadamente en lo social, surge la posibilidad de liberarse de la subordinación asociada a la desigualdad de las mujeres y a la heterosexualidad obligatoria ${ }^{17}$. Para esta autora no sólo no se nace mujer, sino que resulta fundamental evitar convertirnos en una.

La renuncia y el desplazamiento de la categoría mujer a través del estallido del contrato social binario que la delimita, permitirá reorganizar la sociedad desde nuevos paradigmas que desterritorialicen el pensamiento heterocentrado ${ }^{18}$. En la mirada de Wittig, las lesbianas son la figura clave de este esquema de quiebre, toda vez que, como desertoras de los sistemas de sentido asociados al mandato

14 Monique Wittig, El pensamiento heterocentrado y otros ensayos (Córdova: Bocavulvaria ediciones, 2017), 20.

$15 \quad$ Ibíd., 22-23.

$16 \quad$ Ibíd., 33.

17 El concepto de heterosexualidad obligatoria fue desarrollado por Adrianne Rich, y es fundamental para comprender una buena parte de las teorías lesbianas radicales de las décadas de los ochenta y noventa. Para profundizar sobre esta idea, recomiendo la revisión de Adrianne Rich, "Heterosexualidad obligatoria y existencia lesbiana", en Sangre, pan y poesía. Prosa escogida 1979-1985 (Ciudad de México: Prensa Editorial LeSVOZ, 2012).

18 No debería extrañarnos que, desde las filosofías feministas, diversas voces hayan planteado análisis en los que el despliegue de la heterosexualidad (entendida como un marco regulatorio de las normas sexuales y las identidades sexo-genéricas) se piense como fuertemente ligada a las estructuras de producción -y también de la reproducción de la mano de obra- al interior de las sociedades capitalistas. Esto plantea interesantes desafíos para el despliegue de las políticas feministas, puesto que, tal como plantea Donna Haraway, "si el capitalismo y el patriarcado son un solo sistema, llamado patriarcado capitalista, entonces la lucha contra las opresiones de clase y de género debe ser unificada". Donna Haraway, Ciencia, cyborgs y mujeres: la reinvención de la naturaleza (Madrid: Editorial Cátedra, 1995), 236. 
heterosexual, logran escapar de las categorías de sexo abriendo paso a nuevas formas de significación de sí y de relación con otros ${ }^{19}$. "Las lesbianas no son mujeres" ${ }^{20}$ es la frase con la que esta autora ofrece una salida alternativa al llegar a ser mujeres en el que insiste De Beauvoir, intentando desmontar los imaginarios del sexo y el género como estructuras constitutivas inapelables. Lesbiana, insiste Wittig, no es una identidad sexual, sino el nombre que designa a un individuo cuya renuncia a los marcos del pensamiento heterosexual le posicionan por fuera de la categoría de los sexos.

La figuración" ${ }^{11}$ asociada a El cuerpo lesbiano que propone Wittig "hace resaltar el carácter construido, la artificialidad [y] la monstruosidad del "cuerpo femenino"22. La lesbiana abre líneas de fuga respecto del porvenir que se impone a las mujeres, desmontando los mandatos de un sistema que se imagina "si no como natural, al menos como socialmente normativo o incluso simbólicamente preferente" ${ }^{23}$. La figuración de la lesbiana que articula Wittig, opera por sobre y en contra de la certeza principal de la regulación normativa de la heterosexualidad obligatoria: "serás heterosexual o no serás"24. Esta figura puede ayudarnos a extremar la pregunta sobre los modos en los que es posible pensar posiciones políticas que se sitúen más allá de la categoría de sexo, entendiendo que el desmontaje de sus

19 Me parece que sería interesante sugerir aquí, al menos, la posibilidad de una lectura cruzada entre Wittig y Foucault, como una forma de imaginar una nueva ética de la sexualidad lesbiana. ¿Qué podría pasar si nos aventuramos a leer los gestos de renuncia a la heterosexualidad obligatoria que propone Wittig, de la mano de El uso de los placeres -segundo volumen de la historia de la sexualidad? Quizás desde aquí podríamos imaginar nuevas formas de pensar en la potencia que se desata frente al gesto consiente de subvertir las normas de la templanza, para, a partir de la puesta en práctica de nuevas formas de placer, entendidas como técnicas de (de) construcción y producción de sí, hacerse un cuerpo lesbiano más allá de las normas que posibilitan la existencia y el reconocimiento de los sexos. Ver Michel Foucault, Historia de la sexualidad. 2- El uso de los placeres (Buenos Aires: Siglo Veintiuno editores, 2003).

20 Wittig, El pensamiento heterocentrado, 52.

${ }^{21}$ Al utilizar aquí la noción de figuración, estoy pensado en las propuestas que la filósofa italiana Rosi Braidotti ha desarrollado en torno a este concepto. Braidotti propone que "el sujeto del feminismo no es la mujer como otro complementario y especular del hombre, sino un sujeto encarnado, complejo y multiestratificado, que ha tomado sus distancias respecto de la institucionalidad de la feminidad" (Rosi Braidotti, Metamorfosis. Hacia una teoría materialista del devenir (Madrid: Akal ediciones, 2002), 25), y que por lo tanto construye formas alternativas de subjetividad en las que el lenguaje se invoca como un mecanismo para poner en crisis las barreras normativas del género y la identidad. Una figuración feminista invoca el poder de la ironía para desenvolverse en un marco en el que el "como si" desplaza los lugares antes asegurados por la norma. Ver también Braidotti, Feminismo, diferencia sexual y subjetividad nómade, 117.

22 Beatriz Preciado, "Devenir bollo-lobo o cómo hacerse un cuerpo queer a partir de El pensamiento heterosexual", en Teoría Queer. Políticas bolleras, maricas, trans, mestizas, eds. Javier Sáez, David Córdova y Paco Vidarte (Madrid: Editorial Egales, 2005), 126.

23 Beatriz Preciado, Manifiesto contrasexual (Barcelona: Editorial Anagrama, 2011), 83.

24 Preciado, "Devenir bollo-lobo", 127. 
normas da cuenta de una lucha en la que lo que se encuentra en juego es el propio estatuto de lo humano.

Otro elemento fundamental que es necesario tener en cuenta a la hora de pensar en los aportes de la obra de Wittig para el desarrollo de las preguntas que se impulsan desde las filosofias feministas dice relación con sus esfuerzos por revisar y desplazar las normas gramaticales que sostienen y reinscriben a los géneros al interior del lenguaje. Wittig nos invita a pensar en una serie de alternativas desde las cuales sea posible salir de estas relaciones normativas. Para esta autora, la posibilidad de experimentar con "la alteración del género en el nivel epistémico más fundamental estará dirigida, en parte, por la negación de la gramática en la que se produce el género"25. En la obra literaria de Wittig el juego con ciertos pronombres, el descentramiento del yo y la insistencia por imaginar nuevas formas de nombrar, promueve desplazamientos que cuestionan la coherencia y exponen los cimientos que sostienen a las categorías de sexo y a la heterosexualidad obligatoria.

\section{Sexo y género: la diferencia en disputa}

A fines de la primera mitad del siglo XX, el psicoendocrinólogo John Money, junto a su colega Anke Ehrhardt y su equipo de investigadores de la John Hopkins University, impulsaron el desarrollo de una "versión interactiva del paradigma de la identidad genérica" ${ }^{26}$ con la intención de crear una serie de protocolos relacionados al tratamiento de los recién nacidos clasificados como intersexuales, y también para dar una respuesta a ciertos accidentes que supuestamente podían comprometer el desarrollo normal de la identidad de los individuos, afectando su desenvolvimiento en el mundo social. Nacía así el concepto de género, el cual en sus orígenes fue pensado como una herramienta para explicar y, en última instancia, normalizar los mecanismos a través de los cuales la anatomía y los atributos físicos de las personas se traducen en las formas en que éstas, movidas por "la convicción interna de que uno es macho o hembra" 27 , viven y expresan la diferencia sexual. Desde esta mirada, "lo que determina la identidad y el comportamiento de género no es el sexo biológico, sino el hecho de haber vivido desde el nacimiento las experiencias, ritos y costumbres atribuidas a cierto género" 28 . Para integrarse exitosamente en $l o$ humano y volverse inteligible en los horizontes sociales y culturales que habitamos, es requisito fundamental interiorizar adecuadamente los mecanismos diferenciadores

25 Judith Butler, El género en disputa: el feminismo y la subversión de la identidad (Barcelona: Editorial Paidós, 2007), 23.

26 Haraway, Ciencia, cyborgs y mujeres, 226.

27 Anne Fausto-Sterling, Cuerpos sexuados: la política de género y la construcción de la sexualidad (Barcelona: Editorial Melusina, 2006), 23.

28 Marta Lamas, Cuerpo: diferencia sexual y género (Ciudad de México: Editorial Taurus, 2002), 35. 
del género y, al mismo tiempo, cumplir de forma exitosa con las exigencias normativas que se asocian a ellas.

No debiera extrañarnos que el concepto género, que aparecía como una salida frente a las estructuras que ligaban lo masculino y lo femenino a una naturaleza inamovible, volviendo posible así el surgimiento de reflexiones críticas sobre las formas en las que las conductas supuestamente inherentes a los hombres y las mujeres eran aprendidas y reproducidas culturalmente, sobrepasara con rapidez las barreras de las disciplinas que lo vieron nacer. Hacia la década de 1970, la separación entre sexo y género, sustentada en la idea de que "el sexo representaba la anatomía y la fisiología, y el género daba cuenta de las fuerzas sociales que moldeaban la conducta"29, se posicionó con fuerza en los horizontes ligados a las ciencias sociales y a las teorías feministas, dando paso a interesantes debates que aún hoy tensionan las posibilidades de pensar en torno a los problemas y desigualdades históricamente enfrentados de las mujeres.

En su destacado y premiado libro La invención de las mujeres. Una perspectiva africana sobre los discursos occidentales del género, Oyèrónkẹ Oyěwùmí señala que "durante siglos la idea de que la biología es destino - o mejor aún, que el destino es biológico- ha sido fundamental en el pensamiento occidental [y que] las explicaciones biológicas parecen tener prioridad sobre otras alternativas de la explicación de las diferencias de género, raza o clase" ${ }^{30}$. Según Oyěwùmí el pensamiento occidental insiste en apuntar que "la diferencia se extiende como degeneración" 31 y que, por lo tanto, las formas en las que se despliega la percepción de los otros están siempre ligadas a una serie de imaginarios que posicionan en su centro nociones tales como desventaja, privilegio, acceso y control. Para esta autora el concepto género "conceptualizado ontológicamente" ${ }^{\prime 32}$ desplaza a las mujeres como lo otro de lo masculino, inscribiendo las desigualdades en los cuerpos, al tiempo que permite la articulación y el despliegue ad infinitum de una serie de estructuras binarias de diferencia y privilegio, ya que "ninguna diferencia se elabora sin cuerpos jerárquicamente posicionados"33.

A partir de un análisis similar, Donna Haraway ha planteado que "la propia constitución del género y del sexo como objetos de estudio forma parte de la reproducción del problema: el problema de la génesis y del origen"34, puesto que, las formas en que estos conceptos fueron pensados potenció nuevamente la idea de que es posible identificar un núcleo natural incuestionable - $\mathrm{el} \mathrm{sexo-}$ sobre el cual

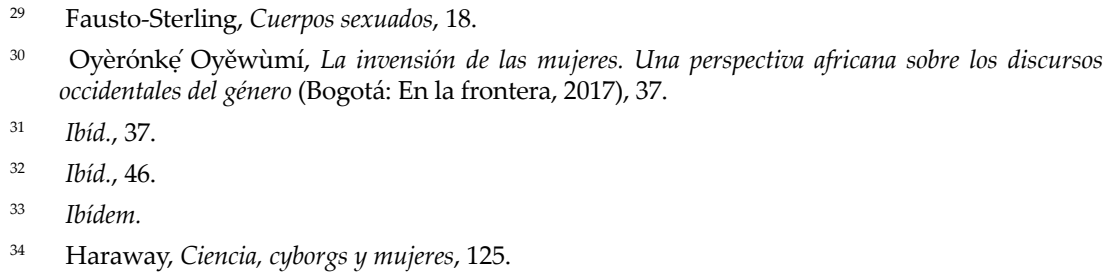


se anclan las diferencias culturales entre hombres y mujeres -el género-. Así, los propios sistemas de análisis mediante los cuales se auspiciaba la renovación de los estudios sobre las desigualdades entre hombres y mujeres, y se suponía la posibilidad de impulsar nuevas formas de emancipación derivadas de la crítica al esencialismo de los discursos patriarcales, terminaron por crear y volver a limitar la categoría de "las mujeres"' ella y el sexo una nueva linealidad insalvable. Lo que las reflexiones que utilizan la categoría de género como herramienta de análisis no deberían olvidar nunca es que la "naturaleza es algo construido, constituido históricamente, [que] no se descubre desnuda en un lecho de fósiles o en una selva tropical" 36 , y que perder de vista esta realidad, o simplemente pasarla por alto, puede dar espacio para el surgimiento de formas teóricas que reinscriban las mismas formas de dominación, segregación y violencia que supuestamente están tratando de criticar y desplazar.

Uno de los principales puntos de conflicto respecto a la utilización de la categoría de género, además de la excesiva facilidad con que a partir de ella la naturaleza volvía a dejarse intacta, estuvo relacionada con el sentido de universalidad que se desprendía de sus análisis. Al ser pensada como una herramienta capaz de explicar las características de (todas) las mujeres, la categoría insiste con demasiada frecuencia en los procesos de articulación de los imaginarios normativos dominados por las estructuras de la heterosexualidad, la familia nuclear y la maternidad, tendiendo a profundizar la invisibilización de las diferencias existentes entre distintos grupos de mujeres y entre los propios grupos internamente, propiciando así el desarrollo de lecturas parciales y la relevación de ciertas historias como más reales o, por lo menos, más importantes que otras. Asimismo, es importante destacar que ciertas recepciones mayoritarias de la categoría de género presentan también un problema que las relacionaba con distintas formas de reinscripción de imaginarios coloniales y racistas, puesto que sus reflexiones y análisis se encuentran, muchas veces, excesivamente centradas en las realidades occidentales ligadas a las mujeres blancas, potenciando - tal como señalan Chandra Tapalde Mohanty y M.Jacqui Alexandercontradicciones, sensaciones de "alienación, dislocación y marginación"37.

A partir de la década de 1980, se levantaron una serie de críticas que pusieron en tensión el uso del concepto género, no sólo en los espacios académicos, sino también en aquellos ligados a los movimientos feministas que buscaban desmontar los anclajes de las violencias relacionadas con las estructuras normativas de la sexualidad, la clase, la raza y un conjunto de otras múltiples diferencias que se conjugan

35 Butler, El género en disputa, 48.

36 Haraway, Ciencia, cyborgs y mujeres, 177.

37 M. Jaqui Alexander y Chandra Tapalde Mohanty, "Genealogías, legados, movimientos", en Otras inapropiables. Feminismos desde las fronteras, bell hooks et al. (Madrid: Traficantes de sueños editores, 2004), 139. 
interseccionalmente para dar forma a las distintas experiencias que constituyen a los sujetos. Así, los feminismos negros, las teorías lesbianas, las escrituras de las mujeres de color, las miradas feministas ligadas al desarrollo del pensamiento postcolonial y las críticas feministas descoloniales denunciaron que la utilización del concepto de género, articulado en solitario y al margen de otras estructuras normativas, reinscribe nuevas formas de violencia y exclusión, impulsando ideales y miradas reduccionistas acerca de lo femenino y lo masculino. Haciendo eco de esta crítica, la teórica feminista estadounidense bell hooks ${ }^{38}$ ha señalado que la teoría feminista no puede agotarse en el género ni contentarse únicamente con reflexionar en torno a la categoría mujer, sino que más bien debe ocuparse de pensar críticamente en torno del conjunto de elementos que "crean diferencias en la calidad, en el estilo de vida y en el estatus social que están por encima de las experiencias comunes que las mujeres comparten"39.

En una carta abierta escrita a modo de respuesta frente a la publicación del libro Gyn/Ecology, de la teórica lesbofeminista Mary Daly en 1978, Audre Lorde insiste en que "dar a entender que todas las mujeres sufrimos la misma opresión por el simple motivo de que somos mujeres es perder de vista los múltiples y variados mecanismos de que se vale el patriarcado. Es pasar por alto el que las propias mujeres utilizamos sin querer esos mecanismos las unas contra las otras" ${ }^{40}$. Podemos leer en una dirección similar las reflexiones que Angela Davis propone en textos como su ya clásico Mujeres, Raza y Clase o el recientemente compilado Una historia de la conciencia, desde los cuales nos impulsa a pensar en torno a los procesos de repetición de las estructuras racistas al interior de los espacios de mujeres y del mundo feminista que se desarrolló en los Estados Unidos durante el siglo XX. Señala Davis:

Es muy posible que las primeras feministas tacharan el matrimonio de "esclavitud" similar a la que padecían negros por el efecto importante de la comparación, por temor a que la seriedad de su propuesta pasase de otro modo inadvertida. Sin embargo, parece que no tuvieron en cuenta el hecho de que equiparar ambas instituciones implica afirmar que la esclavitud no

38 bell hooks es el nombre, pero no uno de nacimiento. Es una forma de reconocerse desde el desplazameinto del propio yo a la hora de escribir. bell hooks es un nombre que se escribe con minúsculas porque quien lo utiliza entiende que la potencia de la voz se ubica más allá de los signos y de la gramática. No hay aquí un error ortográfico, sino un gesto feminista que, deliberadamente, descentra el lugar preferente del yo y del reconocimiento para reflexionar y escribir.

39 bell hooks, "Mujeres negras. Dar forma a la teoría feminista”, en Otras inapropiables. Feminismos desde las fronteras (Madrid: Traficantes de sueños editores, 2004), 37.

40 Audre Lorde, "Carta abierta a Mary Daly", en La hermana, la extranjera: artículos y conferencias (Madrid: Editorial Horas y Horas, 2003), 59. 
era peor que el matrimonio ${ }^{41}$.

La filósofa feminista argentina María Lugones - quien ha dedicado una parte importante de su carrera a desarrollar el concepto de colonialidad del género y que, junto a autoras como Gloria Anzaldúa, Mitsuye Yamada, Cherríe Moraga y Norma Alarcón, formó parte del horizonte cultural de las mujeres de color- lo plantea de la siguiente manera:

Soloalpercibir género y raza como entramados ofusionadosindisolublemente, podemos realmente ver a las mujeres de color. Esto implica que el término "mujer" en sí, sin especificación de la fusión no tiene sentido o tiene un sentido racista, ya que la lógica categorial históricamente ha seleccionado solamente el grupo dominante, las mujeres burguesas blancas heterosexuales y por lo tanto ha escondido la brutalización, el abuso, la deshumanización que la colonialidad del género implica" ${ }^{42}$.

\section{Filosofías feministas y reapropiaciones queer}

Además de las perspectivas que insistían en la necesidad de revisar las formas en las que el concepto género actuaba eclipsando la existencia de diferencias y experiencias diversas entre las mujeres y, también entre éstas y otros grupos. Hacia fines de la década de 1980, las miradas de varias voces ligadas al desarrollo de las filosofías feministas se centraron en repensar desde sus propios lugares algunas importantes propuestas filosóficas del siglo XX, tales como la noción de ideología de Althusser, la idea de poder desarrollada por Foucault, la deconstrucción de Derrida, y también las reflexiones sobre el deseo y el devenir desarrolladas por Félix Guattari y Giles Deleuze. "Lo que estas críticas vinieron a poner en duda era, ni más ni menos, que la propia cuestión de las mujeres como sujeto del feminismo plantea la posibilidad de que no haya un sujeto que exista «antes» de la ley, esperando la representación en y por esta ley" 43 .

En un ensayo clásico titulado "El tráfico de mujeres: notas sobre la 'economía política' del sexo”, la antropóloga feminista y lesbiana Gayle Rubin propuso que ya no era posible seguir pensando la existencia del género al margen del sexo, ya que ambas categorías se encuentran estructuralmente implicadas al interior de un sistema que da cuenta del "conjunto de disposiciones por el que una sociedad

41 Angela Davis, Una historia de la conciencia: ensayos escogidos (Madrid: Editorial Oriente y Mediterráneo, 2016), 93.

42 María Lugones, “Colonialidad y género", Tabula Rasa 9 (2008): 82.

43 Butler, El género en disputa, 48. 
transforma la sexualidad biológica en productos de la actividad humana"44. Esta autora llamó sistema sexo-género a esta conjunción, y propuso la necesidad de utilizar esta nueva categoría para insistir en que "el sexo tal como lo conocemos -identidad de géneros, deseo y fantasías sexuales, conceptos de la infancia- es en sí un producto social" 45 .

Rubin establece un recorrido a través del cual una serie de lecturas entrecruzadas de Marx, Levi-Strauss y Freud le permiten establecer un modelo capaz de explicar las formas en las que las estructuras normativas del sexo generan opresiones diversas y constantes, que se encuentran ligadas a los propios mecanismos mediante los cuales los sujetos llegan a ser de un sexo. Gayle Rubin dirá, pensando en las luchas feministas y sus demandas, que las mujeres "no solamente estamos oprimidas como mujeres: estamos oprimidas por tener que ser mujeres"46. Esta autora insistirá en la urgencia de imaginar, desde los movimientos sociales más críticos, una revuelta que vaya más allá de la simple denuncia de la desigualdad, señalando que "el movimiento feminista (...) tiene que soñar con la eliminación de la sexualidad y los papeles sexuales obligatorios" ${ }^{47}$. Las feministas deben abrirse a la posibilidad de establecer utopías en las que nuevas prácticas de la sexualidad y de identificación se traduzcan en la articulación de comunidades desde las cuales se "trate a todos los principios básicos con una potente dosis de escepticismo"48.

Retomando las reflexiones de Gayle Rubin, Teresa de Lauretis publicó una serie de ensayos sobre sexo, género y teoría feminista que inauguraron una nueva forma de reflexión crítica sobre estos conceptos. Las propuestas de Teresa de Lauretis han sido definidas como piezas fundamentales para comprender el desarrollo y surgimiento de la teoría queer. El concepto "teoría queer" surgió en 1990, ligado a un taller y un conjunto de publicaciones organizados por De Lauretis en la Universidad de California. Según ha declarado la propia autora, con la articulación de este concepto se buscaba proponer una provocación que tensionara, al mismo tiempo, a los estudios gay-lésbicos, al feminismo y a las teorías sobre género. En inglés, queer es un insulto de carácter homofóbico ${ }^{49}$, y sin embargo durante las revueltas homosexuales de las década de 1960 y 1970 -asociadas principalmente a las respuestas de resistencia espontaneas que surgían frente al desarrollo sistemático de redadas policiales en los bares de homosexuales, lesbianas y travestis de distintas

44 Gayle Rubin, "El tráfico de mujeres: notas sobre la 'economía política' del sexo", Nueva Antropología 30 (1986): 97.

$45 \quad$ Ibíd., 103.

$46 \quad$ Ibíd., 135.

$47 \quad$ Ibídem.

48 Gayle Rubin, Deviations: A Gayle Rubin Reader (Durham, NC: Duke University Press, 2011), 253.

49 Trasladado a nuestras latitudes, el término queer podría ser traducido como tortillera, marica, pervertido, travesti, rarito, torcido, colipato o camiona, entre otros. 
ciudades de Estados Unidos- este concepto comenzó a ser reapropiado por las mismas comunidades que se enfrentaban cotidianamente a su violencia. En este proceso surgieron nuevas formas de reconocimiento marcadas por un fuerte espíritu antiheteronormativo $^{50}$. La crisis de la representación ligado al movimiento LGBT en sus variantes liberales, las interpelaciones feministas sobre la identidad surgidas desde los movimientos de mujeres tercermundistas, negras y de color, y la crisis del sida son tres elementos clave que marcan el contexto de surgimiento y las tensiones de la teoría queer, dando cuenta de su giro utópico y orientando sus reflexiones sobre las sexualidades y lo político.

En La tecnología del género, escrito en 1987, De Lauretis parafrasea a Althusser y lleva su pensamiento más allá de sus propias preocupaciones y resguardos, al insistir en que para reflexionar en torno al concepto de género y sus efectos, debemos poner énfasis en la noción de ideología. Según esta autora "el género tiene la función (que lo define) de constituir individuos concretos en cuento hombres y mujeres" 51 . Género, para De Lauretis, es una categoría atravesada de principio a fin por distintos vínculos y relaciones sociales ${ }^{52}$ : "el género representa no un individuo sino una relación, y una relación social; en otras palabras, representa un individuo por una clase" ${ }^{53}$. En el centro de su análisis sobre la tecnología del género, esta autora pone la idea de la representación, insistiendo en que esta es una parte fundamental de sus procesos de articulación normativa y señalando que "la representación del género es [también] su construcción" ${ }^{54}$. Reflexionando sobre el género desde esta perspectiva, De Lauretis, tensiona la forma en que buena parte de los estudios feministas de las décadas anteriores se habían acercado a este concepto.

Releyendo a Foucault, De Lauretis insiste en que "el género, como la sexualidad, no es una propiedad de los cuerpos o algo que existe originariamente en los

50 Es necesario dar cuenta de los modos en los que lo queer trae a nuestra memoria otros procesos de resignificación del lenguaje a partir de los cuales, a largo del siglo XX, se intentaron estructurar formas de reconocimiento y acción colectiva impulsadas por gestos de reapropiación del agravio. Destacan aquí, por ejemplo, la frase black is beautiful asociada a los movimientos sociales que, a partir de la década de los sesenta, cambiaron los modos de significar las luchas negras en EE. UU, y el brown power, que en la misma década marcó los modos de reconocimiento de los chicanos movilizados en torno a las demandas de La Raza y las huelgas de las uvas, encabezadas por activistas como Cesar Chávez y Dolores Huerta.

51 De Lauretis, Diferencias, 39. La frase de Althusser que retoma De Lauretis en esta sección de su ensayo es la siguiente: "Toda ideología tiene la función (que la define) de 'constituir' individuos concretos en cuanto sujetos". Louis Althusser, "Ideology and Ideological State Apparatuses (Notes Towards an Investigation)", en Lenin and Philosophy (Nueva York: Monthly Review Press, 1971), 171.

52 Se observa la fuerte influencia del horizonte filosófico feminista materialista en esta reflexión de De Lauretis, la cual la vincula a autoras como Christine Delphy, Colette Guillaumin y, sobre todo, Monique Wittig.

53 De Lauretis, ibíd., 38.

$54 \quad$ Ibíd., 36 
seres humanos", sino que es "el conjunto de los efectos producidos en cuerpos, comportamientos y relaciones sociales" 55 . Lo interesante aquí, es el giro que ofrece De Lauretis a la hora de intentar romper con la linealidad normativa que asegura que todo individuo tiene siempre un sexo, un género y una sexualidad, y que cada una de las partes de esta supuesta cadena irrompible depende o se desprende de la anterior. Si Foucault asegura que "no hay que poner el sexo del lado de lo real y la sexualidad del lado de las ideas" $"$, De Lauretis dirá, releyendo a Catherine MacKinnon ${ }^{57}$, que "sexo significa tanto sexualidad como género, y ambos conceptos se suelen definir en función uno de otro, en un círculo vicioso" 58.

Así como De Lauretis, Judith Butler también ha reflexionado arduamente sobre la necesidad de centrar críticamente la mirada en la perspectiva relacional del género y en sus potencias creativas en relación con la categoría de sexo. Según esta autora, "el género no designa a un ser sustantivo, sino a un punto de unión relativo entre conjuntos de relaciones culturales e históricas específicas" 59 . Respondiendo a las ideas humanistas que asumen que el género debería ser contado como un atributo que pertenece a una persona cuya esencia puede ser rastreada con anterioridad al género, y desafiando al mismo tiempo las perspectivas culturalistas que afirman que el género es la manifestación cultural de un sexo biológico que lo excede y antecede, Butler afirma que debido a que las estructuras que dan cuenta de la existencia del sexo operan siempre al interior de discursos, y que se encuentran mediadas por el lenguaje. Es necesario entonces desmontar las creencias sobre su supuesta naturaleza, pues "quizás esta construcción denominada 'sexo' esté tan culturalmente construida como el género; de hecho, quizá siempre fue género, con el resultado de que la distinción entre sexo y género no existe como tal”"60. Butler propone un modelo a partir del cual el género y sus normas deben comenzar a pensarse ya no como efectos de una relación con la naturaleza y la biología, sino como el desenvolvimiento de una serie de reglas que contienen la capacidad de crear aquello que se proponen describir. Según esto, "el campo de la realidad que crean las normas de género constituye el telón de fondo sobre el cual aparece el género en sus dimensiones idealizadas" ${ }^{\prime 61}$.

55 Ibídem. Esta cita corresponde a Michel Foucault, Historia de la sexualidad. 1- La voluntad de saber (Buenos Aires: Siglo Veintiuno editores, 2003), 127.

56 Foucault, Ibíd., 191.

57 Ver Catherine MacKinnon, “Feminism, Marxism, Method, and the State: An Agenda for Theory", Signs 7, no. 3 (1982).

58 Teresa De Lauretis, Alicia ya no: feminismo, semiótica, cine (Madrid: Ediciones Cátedra, 1992), 264.

59 Butler, El género en disputa, 61.

$60 \quad$ Ibíd., 55.

61 Judith Butler, Deshacer el género (Barcelona: Editorial Paidós, 2006), 83. 
Si tuviéramos que explicar las estrategias teóricas utilizadas por Judith Butler para reflexionar en torno al género, sin duda la noción en la que debiéramos centrar la mirada está asociada al concepto de performatividad. Butler ha señalado que la lectura "Ante la ley", ofrecida por Jacques Derrida acerca del texto de Kafka, le permitió reflexionar en torno a la potencia de la performatividad del género, toda vez que allí se ofrece una mirada en la que se asume que "la anticipación de una revelación fidedigna del significado es el medio a través del cual esa autoridad se instala: la anticipación conjura su objeto"62. Según Butler, al pensar en el género enfrentamos un proceso de despliegue normativo en el que "una expectativa (...) acaba produciendo el fenómeno mismo que anticipa" ${ }^{\text {"63 }}$. La materialización de las normas que ordenan el género y lo producen, en tanto que conjunto incardinado de regulaciones, requiere del despliegue de la reiteración y la revisión constante de sus límites como modo de inscripción de la diferencia y lo normal. La construcción no es un proceso cerrado que tenga un inicio y un fin siempre definidos, más bien se trata de un conjunto de acciones superpuestas, nunca completamente coherentes o lineales, que operan de modos diversos y con distintas intensidades a lo largo de toda la vida de los individuos. Es la potencia performativa de la reiteración lo que produce el efecto de lo eterno. Sara Ahmed, retomando el modelo de Butler, también insiste sobre este punto y señala que "los cuerpos adoptan la forma de las normas (...) La labor de la repetición supone ocultar el trabajo bajo el signo de la naturaleza" ${ }^{64}$. Sin embrago, no debemos perder de vista que es en el desenvolvimiento estallado de la repetición de la norma donde "en virtud de esta misma reiteración se abren brechas y fisuras que representan inestabilidades constitutivas de tales construcciones" ${ }^{\prime 65}$.

Butler ha propuesto que la importancia de las normas de género radica en que estas tienen la capacidad de definir "lo que será inteligiblemente humano y lo que no, lo que se considerará «real» y lo que no" ${ }^{\text {66 }}$. Quisiera detenerme brevemente en la necesidad de reflexionar en torno a los problemas que supone enfrentarse a la imposibilidad de calzar con la norma. Es necesario pensar sobre los peligros que supone la existencia de un sistema de inscripción y reconocimiento que delimita lo posible y lo deseable, por un lado, y señala como lo abyecto, lo peligroso, lo errado y lo condenable aquello que queda por fuera y lo excede. En palabras de Butler: "El 'sexo' no es pues sencillamente algo que uno tiene o una descripción estática de lo que uno es: será una de las normas mediante las cuales ese 'uno' puede llegar a

62 Butler, El género en disputa, 17.

63 Ibíd., 17.

64 Sara Ahmed, La política cultural de las emociones (Ciudad de México: Programa Universitario de Estudios de Género/Universidad Nacional Autónoma de México, 2015), 222.

65 Judith Butler, Cuerpos que importan: sobre los límites materiales y discursivos del "sexo" (Buenos Aires: Editorial Paidós, 2008), 29.

66 Butler, El género en disputa, 28. 
ser viable, esa norma califica un cuerpo para toda la vida dentro de la esfera de la inteligibilidad cultural"67.

En un apartado titulado "El problema de los servicios", que forma parte de su libro Masculinidad femenina, Judith Halbertam analiza la importancia de revisar las formas en que, en ciertos espacios públicos, los mecanismos a partir de los que se despliegan las demandas normativas del género parecieran volverse más evidentes y vigilantes o, al menos, son invocados con mayor frecuencia, poniendo en peligro la integridad física y psíquica de quienes fallan en la prueba de inteligibilidad del género. Tomando como ejemplo su propia experiencia en un aeropuerto, y refiriendo también a un pasaje de la novela Stone Butch Blues de Leslie Feinberg ${ }^{68}$, en el que el personaje principal, una joven butch de nombre Jess es interpelada y acosada al interior de un baño público debido a que su imagen no es decodificada adecuadamente como la de una mujer, Halbertam concluye que:

La acusación "estás en los servicios equivocados" en realidad quiere decir dos cosas distintas. En primer lugar, afirma que tu género no coincide con tu sexo (...); en segundo lugar, sugiere que los servicios con un solo género son sólo para aquellas personas que encajan claramente en una categoría (varón) u otra (mujer) ${ }^{69}$.

Halbertam insiste en la necesidad de no perder nunca de vista los modos en los que este tipo de guiones reinscriben lo natural, delimitan lo abyecto y definen formas de control y violencia sobre las vidas de las personas que son marcadas como los otros. Reflexionando desde una perspectiva similar que problematiza lo cotidiano como el lugar de rearticulación de las normas, Sarah Ahmed nos recuerda que "no es casualidad que la heterosexualidad obligatoria funcione con mucha fuerza en los modos de conversación más informales" ${ }^{70}$, puesto que es justamente allí, en lo cotidiano y en aquello que nos parece más simple, más obvio y más corriente, donde se juegan y refuerzan las narraciones normativas de la heterosexualidad.

La posibilidad de poner en marcha las subjetividades queer abre paso a nuevos escenarios en los que la revisión de las categorías de sexo y género permite el desarrollo de nuevas figuraciones para habitar el cuerpo, dando curso al desarrollo de "un estilo de pensamiento que evoca o expresa salidas alternativas a la visión

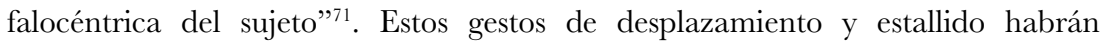

67 Butler, Cuerpos que importan, 19.

68 Leslie Feinberg, Stone Butch Bblues: A Novel (Nueva York: Alyson Books, 2003)

69 Judith Halberstam, Masculinidad femenina (Barcelona: Editorial Egales, 2008), 46.

70 Ahmed, La política cultural de las emociones, 226.

71 Rosi Braidotti, Sujetos nómades: corporización y diferencia sexual en la teoría feminista contemporánea (Buenos Aires: Editorial Paidós, 2000), 26. 
de encontrarse siempre atados a la idea de lo efímero, y ya no a la búsqueda de verdades o esencias. Así, por ejemplo, la figura del cyborg definido por Donna Haraway despliega la monstruosidad como un poderoso mito de resistencia frente aquellos discursos que pretenden normalizar la experiencia del cuerpo y la historia, entendiendo que en ella se entreteje una compleja red de relaciones de producción que se desenvuelve en distintas escalas. Para Haraway, "la ficción puede ser movilizada para provocar identificaciones y oposiciones, divergencias y convergencias en mapas de la conciencia"72. Así, la gran apuesta debiera estar marcada por la posibilidad de fracturar los aparatajes que sostienen la idea de la neutralidad de lo visto, señalando que "el género es una condición inexcusable de la observación [tanto] como la clase, la raza y la nación"73.

En los albores del milenio "el problema último [es] desvelar el carácter técnicamente construido de los géneros, tanto de la masculinidad como de la feminidad"74. Las tecnologías prostéticas serán incorporadas como partes constituyentes e inseparables de nuestros cuerpos y, al mismo tiempo, como dispositivos de control y lugares para la transgresión de los mandatos que articulan los cuerpos y los vuelven reconocibles ${ }^{75}$. Esta vez, hacerse un cuerpo para subvertir las normas pasará por la necesidad de transformar los propios sentidos de lo bio y lo tecno, por contaminar los límites entre subjetividad, cuerpo, experiencia e identidad.

\section{Breve reflexión final}

Cuando reflexionamos en torno a los conceptos sexo, género y mujeres, nos enfrentamos a un conjunto de preguntas y tensiones nunca cohesionadas y siempre en proceso construcción, que nos impulsan a pensar acerca de "qué es una mujer, cómo vamos a decir "nosotras", quién lo puede decir y en nombre de quien"76. Urge

$72 \quad$ Ibíd., 193.

$73 \quad$ Ibíd., 177.

74 Beatriz Preciado, Testo yonki (Madrid: Editorial Espasa Calpe, 2008), 149.

75 Estoy pensado aquí en las píldoras anticonceptivas y a los usos específicos de ciertas hormonas; en el uso del plástico y la silicona como material que adiciona, reconstruye o da nuevas formas -temporal o permanentemente- a nuestros cuerpos; en las tecnologías de la comunicación y las cámaras, que tensionan las formas en las que desarrollamos la mirada y que nos permiten grabar, distribuir, acercar y volver virales los gestos y los deseos; en aplicaciones y programas tales como Tinder, Grinder y Her que transforman nuestros mapas perceptivos de la ciudad dotando cada rincón con nuevos significados asociados al deseo, al placer y a la posibilidad de citas o encuentros sexuales que son ofrecidos en base a complejos algoritmos de compatibilidad y distancia. Hablamos aquí de nuevas formas de cuerpo tech presentes en nuestro mundo hiperconectado y global.

76 Butler, Deshacer el género, 248. 
pensar acerca cuáles son los nombres y figuraciones que es conveniente rescatar y (re)crear a la hora de imaginar políticas y filosofias feministas que se ocupen de desmontar y de no volver a inscribir aquellos modos de subjetivación que impiden la revisión crítica de las diferencias que estructuran nuestras experiencias individuales y también colectivas. Feminismo es una "palabra doble que interroga sin cesar a las mujeres y a la política" $"$, puesto que, al mismo tiempo que en su nombre se despliegan reflexiones que se esfuerzan por abrir campos desde los que se vuelva posible reconocer, articular y proteger los derechos humanos de las mujeres, se desarrollan también críticas y preguntas que dan cuenta de la urgente necesidad de repensar y desensamblar las estructuras a partir de las cuales la propia categoría mujer ha sido producida.

Debemos comprender que "el sujeto de la conciencia feminista no es un sujeto unitario, siempre igual a sí mismo, dotado de una identidad estable; ni un sujeto únicamente dividido entre masculinidad y feminidad" ${ }^{\text {". }}$. Muy por el contrario, poniendo como centro un debate que piensa los espacios de enunciación del yo y las identidades como siempre "marcadas por la multiplicidad de posiciones de sujeto que constituyen al sujeto" "79, las filosofias feministas intentan dar cuenta del conjunto relaciones sociales, experiencias y articulaciones del poder que constituyen a los sujetos al interior de marcos históricos y políticos específicos.

Los recorridos históricos y teóricos propuestos en este texto intentan señalar las múltiples rutas desde las que es posible rastrear y seguir los debates en los que sexo, género y mujeres son constituidos como términos en disputa al interior de los horizontes filosóficos feministas. Salta a la vista que el tema no está resuelto y que aún es posible -y por cierto urgente- seguir imaginando nuevos giros, reapropiaciones y reclamos desde donde imaginar articulaciones que desplacen los límites de lo reconocible y lo humano, a fin de estallar los mandatos normativos que coaccionan nuestras diferencias y buscan reorientarlas. Más aún, se vuelve imperativo volver a remover los marcos desde los que se han desarrollado los debates filosóficos sobre el feminismo, la identidad las experiencias y el género, rescatando los conceptos no sólo más allá de sus propios espacios de enunciación, sino arrastrándolos hacia nuevos desafios, para experimentar con otras referencias, localizaciones y nombres.

Insistir en la necesidad de pensar sobre sexo, género y mujeres es arriesgarse a imaginar nuevos mundos posibles e invitarlos a entrar en nuestras propias configuraciones y representaciones de lo que somos y nos rodea, asumiendo todos los riesgos, desafios y renuncias que puedan derivarse de dichos cambios. Volver

77 Alejandra Castillo, Julieta Kirkwood: políticas del nombre propio (Santiago de Chile: Editorial Palinodia, 2007), 17.

78 De Lauretis, Diferencias, 134.

79 Avtar Brah, Cartografías de la diáspora. Identidades en cuestión (Madrid: Traficantes de sueños editores, 2011), 152. 
a pensar estos conceptos desde la filosofia es demandar nuevas formas de lucha y arriesgar el cuerpo, para ensanchar los marcos de inteligibilidad. Es atreverse a escribir -tal como dice Judith Butler- dando cuenta "de un deseo de vivir, de hacer la vida posible, y de replantear lo posible en cuanto tal"

\section{Referencias bibliográficas}

Ahmed, Sara."Whose Counting?" Feminist Theory 1, no. 1 (2000): 97-103. . La politica cultural de las emociones. Ciudad de México: Programa Universitario de Estudios de Género/Universidad Nacional Autónoma de México, 2015.

Alcoff, Linda. "Cultural Feminism versus Post-Structuralism: The Identity Crisis in Feminist Theory". Signs 13, no. 3 (1988): 405-436.

Althusser, Louis. "Ideology and Ideological State Apparatuses (Notes Towards an Investigation)". En Lenin and Philosophy. Nueva York: Monthly Review Press, 1971.

Alexander, M. Jaqui y Chandra Tapalde Mohanty. "Genealogías, legados, movimientos". En Otras inapropiables. Feminismos desde las fronteras, bell hooks et al., 137-183. Madrid: Traficantes de sueños editores, 2004.

Brah, Avtar. Cartografias de la diáspora: identidades en cuestión. Madrid: Traficantes de sueños editores, 2011.

Braidotti, Rosi. Feminismo, diferencia sexual y subjetividad nómade. Barcelona: Editorial Gedisa, 2004.

. Metamorfosis: hacia una teoría materialista del devenir. Madrid: Akal ediciones, 2002.

. Sujetos Nómades: corporización y diferencia sexual en la teoría feminista contemporánea. Buenos Aires: Editorial Paidós, 2000.

Butler, Judith. Cuerpos que importan: sobre los límites materiales y discursivos del "sexo". Buenos Aires: Editorial Paidós, 2008.

. Deshacer el género. Barcelona: Paidós, 2006.

. El género en disputa: el feminismo y la subversión de la identidad. Barcelona: Editorial Paidós, 2007.

"Variaciones sobre sexo y género. De Beauvoir, Wittig y Foucault". En Teoría feminista y teoría crítica. Ensayos sobre la politica de género en las sociedades de capitalismo tardío, editado por Seyla Benhabib y Drucilla Cornell, 93-211. Valencia: Edicions Alfons el Magnánim, 1990. 
Castillo, Alejandra. Fulieta Kirkwood: políticas del nombre propio. Santiago de Chile: Editorial Palinodia, 2007.

Davis, Angela Una historia de la conciencia: ensayos escogidos. Madrid: Editorial Oriente y Mediterráneo, 2016.

De Beauvoir, Simone. El segundo sexo. Buenos Aires: Random House Mondadori, 2012.

De Lauretis, Teresa. Alicia ya no: feminismo, semiótica, cine. Madrid: Ediciones Cátedra, 1992.

. Diferencias. Etapas de un camino a través del feminismo. Madrid: Horas y Horas, 2000.

Fausto-Sterling, Anne. Cuerpos sexuados: la política de género y la construcción de la sexualidad. Barcelona: Editorial Melusina, 2006.

Feinberg, Leslie. Stone Butch Blues: A Novel. Nueva York: Alyson Books, 2003.

Foucault, Michel. Historia de la sexualidad 1- La voluntad de saber. Buenos Aires: Siglo Veintiuno Editores 2003.

. Historia de la sexualidad 2- El uso de los placeres. Buenos Aires: Siglo Veintiuno, Editores Argentina, 2003.

Halberstam, Judith. Masculinidad femenina. Barcelona: Editorial Egales, 2008.

Haraway, Donna. Ciencia, cyborgs y mujeres: la reinvención de la naturaleza. Madrid: Editorial Cátedra, 1995.

hooks, bell. "Mujeres negras. Dar forma a la teoría feminista". En Otras inapropiables. Feminismos desde las fronteras, de bell hooks et all, 33-50. Madrid: Traficantes de sueños editores, 2004

Lamas, Marta. Cuerpo: diferencia sexual y género. Ciudad de México: Editorial Taurus, 2002.

Lorde, Audre. "Carta abierta a Mary Daly". En La hermana, la extranjera: artículos y conferencias, 57-64. Madrid: Editorial Horas y Horas, 2003.

Lugones, María. "Colonialidad y género". Tabula Rasa 9 (2008): 25-101.

MacKinnon, Catherine. "Feminism, Marxism, Method, and the State: An Agenda for Theory”. Signs 7, no. 3 (1982), 515-544.

Oyěwùmí, Oyèrónkẹ. La invención de las mujeres. Una perspectiva africana sobre los discursos occidentales del género. Bogotá: En la frontera, 2017.

Preciado, Beatriz. "Devenir bollo-lobo o cómo hacerse un cuerpo queer a partir de El pensamiento heterosexual". En Teoría Queer. Políticas bolleras, maricas, trans, mestizas, editado por Javier Sáez, David Córdova, y Paco Vidarte, 111-131. Madrid: Egales, 2005. 
. Manifiesto contrasexual. Barcelona: Editorial Anagrama, 2011.

. Testo yonki. Madrid: Editorial Espasa Calpe, 2008.

Rich, Adrianne. "Heterosexualidad obligatoria y existencia lesbiana". En Sangre, pan y poesía. Prosa escogida 1979-1985. Ciudad de México: Prensa Editorial LeSVOZ, 2012.

Rubin, Gayle. "El tráfico de mujeres: notas sobre la "economía política" del sexo". Nueva Antropología 30 (1986): 95-145.

. Deviations: A Gayle Rubin Reader. Durham NC: Duke University Press, 2011.

Sánchez, Cecilia. "Institucionalidad de la filosofia en Chile: rutas y quiebres". Solar 11, no. 2 (2015): 145-65.

Wittig, Monique. El pensamiento heterocentrado y otros ensayos. Córdova: Bocavulvaria ediciones, 2017.

Panchiba F. Barrientos. Candidata a doctora en Filosofía por la Universidad de Chile (Santiago, Chile). Historiadora Feminista. Magíster en Historia. Desde 2010 dirige el proyecto Biblioteca Fragmentada (www.bibliotecafragmentada.org). Correo electrónico: panchiba@gmail.com. 